\title{
0278 DRIVING SCHOOL STUDENTS TRAINING WITH THE USE OF A NEW METHOD CONTRIBUTING TO CHANGE IN YOUNG DRIVERS ATTITUDE AND REDUCING THE NUMBER OF ROAD ACCIDENT WITH THEIR PARTICIPATION
}

J Wacowska-Slezak*, A Wnuk Correspondence: Motor Transport Institute, Jagiellonska 80 Warsaw, 03-301, Poland

10.1136/ip.2010.029215.278

The aim of the paper is to present the European Project MODULE CLOSE-TO realisation in Poland. The paper describes main objectives and guidelines of the project. The projects main result should be the development of conditions for unification of drivers training system across Europe by introducing into drivers training new educational module. The module consists in realisation of educational method called peer-to-peer during drivers training, which is taken from addiction treatment prevention in which a peer reports on a problem to another peer. In drivers training, the course participants are confronted with road accident offenders and their stories, which should lead to positive changes in attitudes and behaviours of young drivers and therefore to permanent reduction in number of road accidents and casualties. The preliminary research confirmed that classes with road accident offenders have a positive influence on developing proper attitudes of young drivers. A discussion concentrated on offender, his/her susceptibility to risky behaviours, accidents circumstances, confrontation with its consequences and on serving an adjudged sentence makes an impression on young course participants. The project anticipates introduction of pilot classes in driving schools within the framework of drivers training with participation of road accident offenders and also evaluation of its influence on course participants. The final effect of the project will be the development of conditions for introducing a new educational module into existing drivers training system as well as developing conditions for recruiting accident offenders and actions motivating them to join the project realisation. 